EVIDENCE FROM USA

\title{
SCHOOL/COMMUNITY
} PROGRAMMES

\section{Abstinence under fire}

\section{T G Stammers}

\section{It will take more than condoms to reverse the tide of sexually transmitted infections engulfing Britain's young people}

T he Chief Medical Officer, Sir Liam Donaldson, unequivocally states in his first update for this year, that "Evidence does not exist to suggest that abstinence approaches are effective"1 in reducing teenage pregnancy. This is an extraordinary claim, since there is a wealth of evidence suggesting that abstinence approaches can be very effective in delaying the age of first intercourse, reducing unplanned pregnancy, and lowering rates of sexually transmitted infections.

However unjustified by the evidence, the Chief Medical Officer's claim might at least be understandable if the "safer sex" approaches which have dominated sexual health education in the UK for decades had led to an overall improvement in sexual health, but this is clearly not the case. Under headlines such as "NHS clinics overwhelmed as promiscuity takes its toll on a whole generation", David Hinchliffe, chair of the Commons Health Select Committee inquiry into sexual health stated, "Frankly the whole sexual health service is a shambles. ... do not use the word crisis lightly, but I think we have a crisis here". ${ }^{2}$ The UK still has the highest teenage pregnancy rates in Western Europe (though, as in the USA, they are currently improving). Steep rises in cases of chlamydia (doubled in five years), gonorrhoea (up 86\% in five years), and the resurgence of syphilis look set to continue unabated. Against this background, the Department of Health's cursory dismissal of abstinence education is deeply regrettable.

\section{WHAT ARE ABSTINENCE APPROACHES?}

In the USA, where abstinence education is most widely established, there are two main types of approach: abstinence-only, where the focus is wholly on encouraging teenagers not to have sex, providing a rationale for this lifestyle choice, and equipping them with skills such as assertiveness and self esteem to fulfil this goal. Abstinence-plus programmes present the same message that abstinence is the safest form of protection against pregnancy and sexually transmitted infections but also provide information and advice on contraception.
Abstinence components also play an important part in many contraceptive and safer sex focused programmes in the USA. $^{3}$

There is ample evidence that abstinence approaches overall (whether only or plus) can be effective.

\section{REVIEW EVIDENCE FROM USA SCHOOLS' PROGRAMMES}

In a recent review of six abstinence-only and two abstinence-plus programmes, Thomas notes significant knowledge or attitude changes in four of the abstinence-only programmes and delayed onset of intercourse at six month follow up in one of them. ${ }^{4}$ Both of the abstinence-plus programmes showed significant delay (up to 18 months) in onset of first intercourse among those who were not sexually active at the start of the programme (and, in the one study that looked at this, less likelihood of unprotected intercourse when sex was initiated).

A recent review of reviews by the Health Development Agency dismisses Thomas with the assertion that "no other review included here has identified abstinence-only approaches as successful". ${ }^{5}$ In fact, the review by Card that was included identifies both abstinence-only as well as several abstinence-plus programmes among those that work successfully.

Card reviews 11 primary pregnancy prevention programmes with published evidence of their effectiveness. ${ }^{3}$ Of these, at least three are abstinence based approaches $^{6-9}$ including two which appear to be abstinence-only. Even some of the more contraceptive based programmes included by Card, contained a strong abstinence message (for example, Vincent et $\left.a l^{10}\right)$. Thus, one of Card's conclusions is that, "Abstinence is the gold standard behaviour for teens in middle and high school because, among other reasons, it the only way to be $100 \%$ sure you will not get pregnant or cause a pregnancy to happen". ${ }^{3}$ However, the Health Development Agency review oddly summarises Card on abstinence with the single statement, "Despite strong fiscal support being given to abstinence-only programmes, there is no firm evidence for their effectiveness". ${ }^{\text {. }}$
No school programme as a stand-alone project is likely to achieve the maximum impact in changing sexual behaviour and there is increasing evidence that community based abstinence education can be even more effective.

In the School/Community Program for Sexual Risk Reduction Among Teens in South Carolina, the primary objective was to "delay sexual intercourse among never-married teens and pre-teens". The secondary objective was to encourage contraceptive use among those who did not comply with the primary objective. Courses to communicate these messages effectively were given not only to teachers but also to parents, clergy, and other church leaders and community agency professionals. Newspaper and radio advertising were also utilised extensively to try and achieve saturation coverage in the community of the programme messages. Two and three years into the intervention programme the pregnancy rates for 14-17 year olds in the intervention part of the county showed a "remarkable sustained decline", not observed in the comparison counties.

A more recent paper also describes the highly significant effect of an abstinence program in Monroe County, New York. ${ }^{12}$ This used a mass communications approach including $\mathrm{TV}$, newspaper and radio broadcasting, billboards, and regular community events to promote the "Not Me, Not Now" abstinence education programme, which was used by all 9-14 year olds in the county schools. By the third year after the implementation of the programme, the percentage of students reporting intercourse by the age of 15 had fallen from $47 \%$ to $32 \%$. The slope of the regression line for the fall in pregnancy rates of 15-17 year old girls in Monroe County following the programme was 2-3 times that for the surrounding areas of New York which did not run the programme.

Another community based programme to help adolescents avoid health risk behaviours was presented to children up to age 12 in Seattle. ${ }^{13}$ At nine year follow up after the end of the programme, when they reached age 21 , those in the programme were less likely to have started having sex by age 21 . They were also significantly older at first sexual experience ( $16.32 \vee 15.75$ years), had fewer sexual partners $(3.58 v 4.13)$, were less likely to become pregnant $(38 \%$ $v 56 \%$ ), and were more likely to have used a condom at first intercourse. The striking feature of this programme is that it had no specific sex education component at all, though good decision making (including abstinence) in many 
fields was encouraged more generally. It is quite remarkable that, in the UK, sexual activity is one area in which encouraging abstinence in the under-16s is regarded as an unreasonable goal. We expect our children to abstain from stealing, bullying, and a host of other activities but often imply that it is less important where sexual activity is concerned. This is quite bizarre in view of the fact that a large majority of 12 year olds readily accept abstinence as an appropriate method for them to avoid unplanned pregnancy.

Finally, the effectiveness of abstinence based community projects on changing teenage sexual behaviour is also shown by a comprehensive analysis ${ }^{14}$ of data from the 1994-96 National Longitudinal Study of Adolescent Health. ${ }^{15}$ This concludes that making a virginity pledge (one of the aims of some US abstinence programs) delayed the onset of sexual intercourse by up to three years. Even though this strong effect was conditioned by both age and social context, it still constitutes powerful evidence for the effectiveness of abstinence education within that culture.

\section{UGANDA AND ABSTINENCE}

Evidence from the US is now further supported by results currently emerging from abstinence education projects in several other countries, particularly Uganda, ${ }^{16}$ where $\mathrm{ABC}$ programmes (Abstain, Be faithful, or wear a Condom) are widespread. Dr Anne Peterson, director of global health for the US Agency For International Development stated "Kids are willing and able to abstain from sex. Condoms play a part. They are better than nothing, but the core of Uganda's success story is big A, big B and little $\mathrm{C}^{\prime \prime} \cdot{ }^{17}$

A recent four year study of safer sex interventions in one district of rural Uganda showed no reduction in the incidence of HIV infection. ${ }^{18}$ Another study from the Rakai district, reported no overall protective effect against HIV acquisition in women who reported condom use. ${ }^{19}$ Dr Norman Hearst, the epidemiologist who authored the USAID report on condom efficiency, concludes "There really is not any clear evidence that condom promotion by itself has been able to roll back the AIDS epidemic in any country where there is widespread transmission" ${ }^{17}{ }^{17}$ Indeed the rate of condom use in Uganda remains one of the lowest in Africa, yet several studies have shown the steep decline in rates of HIV infection since 1992. ${ }^{20}$ The prevalence of HIV among pregnant women in Kampala, for example, dropped from $25 \%$ in 1992 to $14 \%$ in 1998 . This same time frame has also seen dramatic changes in sexual behaviour. The percentage of 13-16 year olds who reported having had sex fell from over $60 \%$ in 1994 to $5 \%$ in 2001 for boys and from $25 \%$ to $3 \%$ for girls. ${ }^{16}$ Among women aged 15 and above the number reporting multiple sexual partners fell from $18.4 \%$ in 1989 to $8.1 \%$ in 1995 to $2.5 \%$ in $2000 .^{16}$

Evidence of the effectiveness of the HEART (Helping Each Other Act Responsibly) programme in encouraging sexual abstinence among teenagers in Zambia was recently presented at the 14th World AIDS Congress in 2002 by researchers from Johns Hopkins School of Public Health. ${ }^{22}$ A recent report from Harvard researchers on the stabilisation of HIV rates in Jamaica included the recommendation that "the delay of sexual debut and abstinence messages promoted primarily through school and churches, should continue to be part of the national strategy". ${ }^{23}$

At the UN child summit last year, Uganda's First Lady Museveni was characteristically bold and blunt in stating, "The young person who is trained to be disciplined will, in the final analysis survive better than the one who has been instructed to wear a piece of rubber and continue with 'business as usual'". ${ }^{24}$ The Chief Medical Officer and our own government's Sexual Health Inquiry would have done better to heed such advice, rather than making unhelpful statements ideologically opposed to abstinence education. It will certainly take more than condoms to reverse the tide of sexually transmitted infections currently engulfing young people in Britain.

Postgrad Med J 2003;79:365-366

\section{Author's affiliation}

St George's Hospital Medical School, London

Correspondence to: Dr Stammers;

tgstammers@doctors.org.uk

\section{REFERENCES}

1 Donaldson L. Chief Medical Officer's update 35. London: Department of Health, January 2003 (www.doh.gov.uk/cmo/ cmo_35.htm\# 10)

2 Hartley-Brewer J. NHS clinics overwhelmed as promiscuity takes its toll on a whole generation. Sunday Express 8 June 2003

3 Card J. Teen pregnancy: do any programs work? Annu Rev Public Health 1999;20:257-85.

4 Thomas M. Abstinence-based programs for prevention of adolescent pregnancies: a review. J Adolesc Health 2000;26:5-17.

5 Swann C, Bowe K, McCormick G, et al. Teenage pregnancy and parenthood; a review of reviews. London: Health Development Agency, 2003

6 Donaghue MJ. Technical report of the national demonstration project field test of human sexuality: values and choices. Minneapolis, MN: Search Institute, 1987.
7 Howard M, McCabe JB. Helping teenagers postpone sexual involvement. Fam Plann Perpsect 1990;22:21-6.

8 Howard M, Mitchell M. Preventing teenage pregnancy: some questions to be answered and some answers to be questioned. Pediat Ann 1993;22:109-18.

9 Jorgenson SR, Potts V, Camp B. Project taking charge; six-month follow-up of a pregnancy prevention program for early pregnancy prevention program for early
adolescents. Fam Relat 1993;42:401-6.

10 Vincent ML, Dill H, Johnson C. School/community sexual risk reduction program for teens. Columbia, SC: University of South Carolina School of Public Health, 1987

11 Vincent ML, Clearie AF, Schluchter MD. Reducing adolescent pregnancy through school and community-based education. JAMA 1987; 257:3382-6.

12 Doniger AS, Adams E, Riley JS, et al. Impact evaluation of the "Not Me, Not Now" abstinence-oriented, adolescent pregnancy prevention communications program, Monroe County, New York. Journal of Health Communication 2001;6:45-60 Communication 2001;6:45-60 NMNNimpactevaluation.pdf).

13 Lonczak H, Abbott R, Hawkins D, et al. Effects of the Seattle Social Development Project on sexual behaviour, pregnancy, birth and sexually transmitted disease outcomes by age 2 lyrs. Arch Pediatr Adolesc Med age 21 yrs. Arch Pediat

14 Bearman PS, Bruckner H. Promising the future; virginity pledges and first intercourse. Am J Sociology 2001;106:859-912.

15 Resneck MD, Bean PS, Blum RW, et al. Protecting adolescents from harm: findings Protecting adolescents from harm: findings
from the national longitudinal study on adolescent health. JAMA 1997;278:823-32.

16 Hogle J, Green EC, Nantulya R, et al. Whatever happened in Uganda? Declining HIV prevalence, behaviours change and the national response. Washington, DC: USAIDWashington and The Synergy Project TVT Associates, 2002 (www.usaid.gov/ pop_health/aids/Countries/arrica/ uganda_report.pdf).

17 Carter $\overline{\mathbf{T}}$. Uganda leads by example on AIDS The Washington Times 13 March 2003 (www.washingtontimes.com/world/ 20030313)

18 Kamali A, Quigley M, Nakivingi J, et al. Syndromic management of sexuallytransmitted infections and behaviour change interventions on transmission of HIV- 1 in rural Uganda: a community randomised trial. lancet 2003:361:645-57.

19 Kiddugavu M, Makumbi F, Wawer M, et al. Hormonal contraceptive use and HIV-1 infection in a population-based cohort in Rakai, Uganda. AIDS 2003;17:233-40.

20 Mulder D, Nunn A, Kamali A, et al. Decreasing HIV-1 seroprevalence in young adults in a rural Ugandan cohort. $B M$ 1995;311:833-6.

21 Mbulaiteye SM, Mahe C, Whitoworth JA, et al. Declining HIV-1 incidence and associated prevalence over 10 years in a rural population in SW Uganda: a cohort study. Lancet 2002;360:41-6.

22 Martin K. Zambia's HEART programme evaluation shows youth respond positively to AIDS prevention plan promoting abstinence. Baltimore, MD: Johns Hopkins University Centre for Communications Programmes, 2002 (www.jhuccp.org/pressroom/2002/ 07-1 1.shtml).

23 Amara Singham S, Green E, Royes H. Final evaluation AIDS/STD prevention and control project; Jamaica. Washington, DC: USAID-Washington and The Synergy Project TvT Associates, 2001 (www.synergyaids.com/documents/ 1744_Jamaica_Final_Report.pdf).

24 The Buzz. Available at: www.worldmag.com/world/issue/05-1802/opening_2.asp. 